\title{
NIETZSCHE: RECUSA E CRÍTICA DA PEQUENA POLÍTICA - UMA PERSPECTIVA DA EDUCAÇÃO
}

\author{
Lucia Schneider Hardt ${ }^{1}$ \\ Vilmar Martins ${ }^{2}$ \\ Jonas Faccin ${ }^{3}$
}

\begin{abstract}
RESUMO: Este artigo analisa algumas imbricações entre a pequena política e a educação. A pequena política está imersa na lógica do bem e do mal. Para Nietzsche, moral é apenas uma interpretação de determinados fenômenos, em geral uma má interpretação. A educação tende a aliar-se à pequena política paradoxalmente sempre que pretende dar à formação um caráter de comprometimento com a sociedade, com as instituições escolares, com o melhoramento da humanidade. Ao recusar e criticar as ações no entorno da pequena política, o texto pretende apontar outros caminhos formativos no campo da educação, em vista do cultivo da Grande Política.
\end{abstract}

Palavras-chave: Formação. Pequena política. Moral. Grande política.

\section{Nietzsche: refusal and critical the small politics - an educational perspective}

\begin{abstract}
This article analyzes some connections between small politics and education. Small politics is immersed in a good and evil logic. To Nietzsche, morality is only an interpretation of a given phenomenon, and generally a bad one. Paradoxically, education tends to form alliances with small politics every time it intends to educate in a way that fosters commitment to society, to educational institutions, to the improvement of humanity. By refusing and critiquing actions based on small politics, the goal of this text is to point out other paths in the field of education in order to cultivate Grand Politics.
\end{abstract}

Keywords: Education. Small politics. Morality. Great politics.

\footnotetext{
'Universidade Federal de Santa Catarina. luciashardt@gmail.com

${ }^{2}$ Universidade Federal de Santa Catarina. vilmarmartins@hotmail.com

${ }^{3}$ Colégio Coração de Jesus. profjonasfilosofia@gmail.com
}

$$
\begin{array}{lll}
\text { v. } 21 \text { n. } 46 \quad \text { p. } 124-137 & \text { abr/jun. } 2019
\end{array}
$$




\section{CONSIDERAÇÕES INICIAIS}

"Somente a partir de mim haverá grande política na terra" (NIETZSCHE, 2001, p. 110). Eis a provocação do filósofo do martelo. Bem sabemos que a "performance" nietzschiana perpassa a hipervalorização de sua pessoa e frases de impacto, mas nos atentemos com mais cuidado a essa frase. Conforme Barrenechea (2004), a proposta de grande política nietzschiana perpassa uma transformação axiológica da humanidade. Longe de mudanças nos estratos burocráticos ou de exercício do poder, a grande política levada a cabo pelo filósofo legislador será capaz de criar valores e suscitar novos caminhos para humanidade; esta transvaloração de todos os valores, observada como educação superior da humanidade, possibilitaria a assunção de uma nova era trágica onde o humano transvalorado seria capaz de usufruir da grandeza que é a intensificação plena das suas forças vitais.

Por outro lado, ao se referir à pequena política, Nietzsche remete aos procedimentos políticos dos estados modernos, onde a pequenez da tendência igualitária, ao dissolver as hierarquias, nivela o humano como simples animal de rebanho. Esse apequenamento do tipo moderno levado a cabo pela promoção de valores mesquinhos, tais como os valores econômicos, militares, sociais, etc., que visam ao grupo e não ao desenvolvimento do indivíduo, impede a construção dos grandes valores artísticos culturais e de superação da atual condição humana, pois o tipo moderno visa apenas à sua conservação.

\section{A PEQUENA POLÍTICA E A EDUCAÇÃO}

A pequena política está imersa na lógica do bem e do mal. Para Nietzsche, moral é apenas uma interpretação de determinados fenômenos; em geral, má interpretação. A educação tende a aliar-se à pequena política, paradoxalmente sempre que pretende dar à formação um caráter de comprometimento com a sociedade, com as instituições escolares, enfim, com um suposto melhoramento da humanidade. Para recusar e criticar as ações no entorno da pequena política operamos, "de saída”, a partir de dois conceitos: "código estúpido", cunhado por Larrosa, e "melhoradores da humanidade", expresso por Nietzsche.

Tanto Nietzsche quanto Larrosa em alguma medida concordam que a estupidez é uma forma de abandono do pensamento em sua dimensão 
heurística. Para Larrosa (LARROSA, 2004, p. 50), o pensamento estúpido aparece quando o que pensa em nós - (portanto não é ausência de pensamento) - "é nosso conformismo, nosso afã de segurança, nossa necessidade de ordem, nosso desejo de obedecer". Do outro lado, Nietzsche nos adverte: "chamar a domesticação de um animal sua 'melhora' é a nossos ouvidos uma piada” (NIETZSCHE, 2008, p. 50). No afã de formar, deformamos o humano para depois reivindicar o direito de melhorá-lo. Contornos da pequena política, dirá o filósofo alemão. Isto é, desejo de amansar o que parece excessivamente selvagem. A formação do homem com sentido moral, em geral, sempre foi imoral, instaura-se por meio de códigos estúpidos.

Como prosseguir no debate considerando que os valores da educação estão imersos num conjunto de princípios para melhorar a humanidade? Seria então a educação um lugar para desprezar a virtude? E como pensar o campo da educação sem nenhum telos, sem nenhuma finalidade moral? Talvez a recusa da pequena política signifique, antes de tudo, uma luta contra a estupidez. Ao dar as costas a ela, não está em questão se colocar em algum lugar privilegiado, refugiar-se então em uma soberba arrogância. Pensemos desse lugar, o que é estúpido então no campo da educação: uma ideia de humano amansado, valores que inibem a força do instinto, formas de interpretar que homogeneízam, incitar um pensamento apressado, prescrever condutas e atitudes dadas como ideais. Enfrentar o código estúpido implica dar certa ilegibilidade a essas práticas para iniciar um processo de diferenciação, de uma formação não estúpida.

Nomear o que fazemos em educação nos exigiu até hoje usar palavras. Com elas nomeamos o que supostamente somos, fazemos, desejamos. Elas em muitas situações também são estúpidas, já não mais disputam entre si um espaço em nossos discursos, já foram selecionadas: as mais adequadas e aquelas excluídas, tombadas e já esquecidas. O enfrentamento da estupidez, a recusa da pequena política, poderia começar por aqui. Que palavras foram silenciadas, quais foram desativadas, quais estão impedidas de serem pronunciadas?

As palavras indicam autoridade para medir, classificar e regular a vida das pessoas, dos currículos, da cultura. Paradoxalmente, a sensação é de fadiga, as palavras parecem cansadas. A fadiga indica que antes das palavras temos vivências que talvez precisamos recordar. $\mathrm{O}$ que fazer quando cansamos de usar palavras, pois elas parecem capturadas pelo desejo de pronunciar algum tipo de verdade. A vontade de saber tem de ser convertida em uma vontade de repetir. Parece que precisamos desviar as palavras da velocidade, da pressa, dos espaços 
qualificados que legitimam os discursos; precisamos admitir que para aquilo que temos palavras já foi vivido, portanto ficou para trás. A linguagem, diz Nietzsche, "[...] foi inventada apenas para o que é médio, mediano, comunicável” (NIETZSCHE, 2006, p. 79). As palavras velozes estão atropelando-se para disputar o espaço do direito à visibilidade. Como inserir palavras mais vagarosas que precisam de mais tempo para serem pronunciadas? Palavras capazes de apontar outras experiências. $\mathrm{O}$ silêncio entre as palavras, mais que interrupção são gestos de reflexão, de maturação para dizer o que ainda possa ter sentido e significado. Diante da fadiga parece ser necessário, como diz Nietzsche, deixar-se levar por um "[...] rebelde, arbitrário, vulcânico anseio de viagem, de exílio, afastamento, esfriamento, enregelamento, sobriedade, um ódio ao amor, talvez um gesto e olhar profanador para trás...” (NIETZSCHE, 2000, p. 10), para nessa viagem, sem pressa, com vagar, pensar de novo o que se tem a dizer e a pensar.

A (recusa) da pequena política insere-se também nesta perspectiva: é preciso continuar a ler Nietzsche para compreender o que significa a ideia do cultivo de si que consegue suportar até a suspensão de uma sólida reputação, para viver intensamente e enfrentar inclusive os hábitos duradouros. O duradouro é um código estúpido dos melhoradores da humanidade. Afinal, estamos conseguindo, como educadores, conquistar o privilégio de poder viver por experiência? Ou nossos hábitos têm formatos tão duradouros que já não conhecemos mais o encanto do estranho? Viver por experiência cria a possiblidade de hábitos breves.

Hábitos breves são uma espécie de outra virtude, deslocada de um debate sobre reputação - aquilo que insiste em permanecer igual - pois implicada pela vontade de afirmar a vida por meio da intensidade de sua novidade. Dirá Nietzsche: "É preciso poder sempre enfiar e retirar novamente a cabeça e nada encontrar de habitual ao redor" (NIETZSCHE, 2008, p. 234). A pequena política não suporta a brevidade dos hábitos, necessita de adeptos, de convictos. No Crepúsculo dos ídolos, Nietzsche defende o direito à tolice, à estupidez (NIETZSCHE, 2008). Contudo, sua defesa vai em direção a um homem cansado que necessita de "uma espécie de férias para o espírito". Nesse caso, a estupidez, ao contrário do uso que fizemos até aqui, restaura. Trata-se de outra "tolice", oriunda do cansaço do duradouro, cansaço do peso das obrigações e das exigências dos melhoradores da humanidade. Uma estupidez que não se deixa acomodar aos cantos que o mundo criou para o espírito, mas deseja escapar, impedir que surja o homem altruísta, que, por fim, seria o fim do humano. 


\section{OS VALORES E A EDUCAÇÃO}

Um código estúpido remete a valores estúpidos, valores pequenos, valores de preservação. Quando agimos no horizonte de valores estúpidos damos vazão a uma vida covarde, pequena, medíocre, até mesmo uma ausência de vida, em contraponto aos valores nobres tão apregoados pelo filósofo do martelo.

Nos contornos da pequena política encontramos a dinâmica decadente da cultura judaico-cristã, este germe cultural do Ocidente que, enquanto cultura política, perpassa todo o nosso tecido social, desde as nossas instituições até aos movimentos sociopolíticos. A decadência da pequena política está justamente na absolutização de valores cristianizados, desta forma, torna-se ela a própria negação da política ao negar o jogo de conflitos que marca a gênese do caráter político, para assim pretender-se validade universal, para sempre e para todos. Sustentada em um pseudo-humanismo, a pequena política com seus valores absolutos e universais aniquila as diferenças em nome de uma igualdade para todos; este nivelamento de todos, travestido de humanismo, exala o fétido odor do niilismo, e não esqueçamos: "niilismo é quando os valores supremos se desvalorizam" (NIETZSCHE, 2013, p. 289), ao passo que nada exemplifica melhor a desvalorização que a igualdade, o nivelamento por baixo.

Este niilismo denominado igualdade, sustentado por um processo decadente de autoconservação da vida, iniciou-se com uma proposta de igualdade de direitos e culminou em uma igualdade entre todos - nesses tempos em que a democracia foi alçada a valor universal e a igualdade a uma utopia necessária, convém explicar a recusa pela igualdade. Nossa dificuldade em aceitar a igualdade consiste na pretensão niveladora da mesma, onde tudo o que não pode ser homogeneizado é eliminado, todos que erguem a cabeça para além do rebanho têm sua cabeça cortada, lógica perversa e maniqueísta, como a patética pergunta dos cordeiros na Genealogia da moral "[...] essas aves de rapina são malvadas; e quem é o menos possível uma ave de rapina, antes, porém sua antítese, um cordeirinho, não deveria ser bom?" (NIETZSCHE, 2009, p. 35), ou seja, tornar igual a partir da exclusão das diferenças.

Novamente nos deparamos com o código estúpido, desta vez na estupidez de uma igualdade construída a partir da exclusão das diferenças. Pergunta que ecoa: Como construímos esta igualdade e como a alçamos a valor absoluto? Nietzsche nos auxilia a pensar na direção desta questão, apontando a moral como instrumento da construção de uma natureza igualitária, útil, gregária e de rebanho: 
Conforme nos educam hoje, adquirimos primeiro uma segunda natureza, e a possuímos quando o mundo diz que chegamos a maturidade, emancipados, tornados úteis. Somente um pequeno número é bastante serpente para largar, esta pele um dia, quando sob sua envoltura chegou a maturidade a primeira natureza. Mas na maioria das pessoas o germe se atrofia. (NIETZSCHE, 2008, p. 222)

A segunda natureza adquirida a dispêndio da primeira possui um objetivo claro, nos tornar úteis. Somos úteis quando o que nos resta de individualidade e singularidade não passa da tênue lembrança de uma natureza abandonada. Para Nietzsche, a consolidação desta segunda natureza a partir do amansamento da besta-homem e do cultivo de uma determinada espécie de humano, melhor se exprime em termos zoológicos, pois, assim como duvidamos que as feras expostas nos circos foram "melhoradas", também duvidamos da "melhora" que a moral de rebanho causa na besta-homem.

$\mathrm{O}$ que temos nos circos são feras enfraquecidas, tornadas menos nocivas, a partir do medo, da fome, da dor e dos castigos, ou seja, bestas doentes. Segundo Nietzsche, não foi diferente o que a Igreja fez com o humano na alta Idade Média. Depois de caçar a besta-loura por todas as partes, a Igreja expôs para o mundo os nobres germanos melhorados, ou seja, um aborto de humano, uma caricatura, presa, enjaulada, atormentada por terríveis conceitos, os sacerdotes transmutaram um guerreiro em um pecador. $\mathrm{O}$ que se via era um enfermo, empobrecido, mesquinho, culpado, malevolente para consigo, cheio de ódio para com a vida, ressentido, envenenado por um espírito de vingança, cheio de suspeita para tudo o que ainda se apresentava como forte e feliz, inimigo da alegria, em termos fisiológicos: para combater a besta-humana a Igreja tornou-a doente, estragando, debilitando, mas reivindicando tê-la melhorado.

Este processo exemplifica muito bem a inculcação desta segunda natureza coletivista e gregária. No entanto, longe de defender uma entrega à animalidade e individualidade com a extirpação de qualquer valor comunitário, nossa proposta é pensar um processo para - como recomenda Nietzsche - nos tornarmos serpentes, abandonando esta pele doente, sem atrofiar a primeira natureza, mas entregar-se a ela quando a mesma atingir sua maturidade. Movemo-nos em campo escorregadio, não há linha que separe uma segunda natureza doente de uma primeira natureza que necessita atingir sua maturidade, 
o que temos são graus e intensidades de naturezas em uma disputa titânica pelo domínio deste todo orgânico chamado humano.

Nosso objetivo é pensar uma segunda natureza que não parta da premissa básica de negar uma natureza anterior, sem cair em uma simples aceitação de uma primeira natureza. Para realizar esta atividade, faz-se necessário cavar os substratos obscuros do humano que a natureza política insiste em ocultar. Nossa premissa é questionar a validade da formação moral proposta pela escola, não apenas devido à multiplicidade de valores presente em nossa sociedade, mas voltar nossos martelos contra a moral única proposta pela escola, a doutrinação tão presente em nossos espaços formativos.

Ousamos pensar que longe de uma catequese moral, seria papel das nossas instituições de ensino criar condições de possibilidade para a formação ética, fornecendo espaços para o encontro com o outro, nestes encontros agonísticos formamos e somos formados, nos autoformamos; encontros que não mais formatem os recém-chegados para inseri-los em um mundo préestipulado, mas que observe neste que chega a novidade, a possibilidade e a potência para ir além da sua atual condição, sem a necessidade imediata de ajustar-se à nossa condição.

\section{A GRANDE POLÍTICA E A EDUCAÇÃO}

No entorno das questões que envolvem a educação, de modo específico em oposição às ações da pequena política, surge a emergência da grande política. Neste caso, se com Nietzsche buscamos também nos superar à pequena política, isto é, este constante desejo de amansamento e obediência forjado quase definitivamente em nossas práticas formativas, consideramos que o discurso nietzschiano acerca da grande política está como que associado a um projeto mais profundo de crítica da modernidade, de modo que isso ocorre a partir da superação dos atuais pressupostos que regem o mundo moderno. De acordo com Nietzsche, "todas as leis, segundo as quais a vida se desenvolve, pareciam estar em contradição com os valores em virtude dos quais nós nos mantemos vivos" (NIETZSCHE, 2013, p. 242), sendo este o caráter angular, dirá Nietzsche, "o problema trágico" da modernidade (Idem). Ora, esta falta de harmonia entre os valores modernos e a própria existência parece de fato reger a vida humana. Preterir a elevação do homem corresponde superar as fortes tendências niilistas que em larga escala configuram-se como o problema trágico do mundo moderno. 
Nesse sentido, ao se deparar com a completa falta de sentido da vida imperando na modernidade, Nietzsche terá de buscar uma "profunda transformação axiológica e educativa da humanidade" (BARRANECHEA, 2004, p. 96). Ao propor a superação de uma existência humana decadente, para Nietzsche será preciso (re)pensar de modo profundo a maneira como os homens foram até então educados. Ou seja, tornar-se-á necessário um olhar para a maneira como foi até hoje o homem cultivado, "que tipo de homem se deve cultivar (züchten), se deve querer, como o mais valioso, mais digno da vida, mais certo de futuro" 4 , sobretudo porque através do medo é que foi preterido, cultivado (gezüchtet) e alcançado o tipo diverso: "o animal doméstico, o animal de rebanho, o animal doente homem"5.

Uma vez mais, torna-se central a Nietzsche questionar o tipo de formação que até o momento foi pretendido e cultivado pelos homens, tendo em vista que neles se identifica uma forte predisposição ao cansaço de si mesmos, uma inclinação a um niilismo extremo, a uma vontade de nada:

E precisamente nisso está o destino fatal da Europa - junto com o temor do homem, perdemos também o amor a ele, a reverência por ele, a esperança em torno dele, e mesmo a vontade de que exista ele. A visão do homem agora cansa - o que é hoje o niilismo, se não isto?... Estamos cansados do homem... (NIETZSCHE, 2009, p. 32)

A cultura ocidental criou raízes e vigorou um tipo de homem fraco, um tipo que "se apresenta como a única espécie de homem permitida, e glorifica os seus atributos, que o tornaram manso, tratável e útil ao rebanho" (NIETZSCHE, 2005, p. 86). Para Nietzsche, como contramovimento ao destoante nivelamento que permeia os tempos modernos, a grande política corresponde, de modo decisivo, a um tipo de cultivo capaz de engendrar homens de existência superior, "espíritos fortes e originais o bastante para estimular valorizações opostas e tresvalorar e transtornar "valores eternos"” (Ibidem, p. 91). Será fundamental ao homem colocar-se na disposição de experienciar mecanismos cujas referências não estão mais direcionadas para a eliminação da pluralidade de tipos que marcam existencialmente o seu modo

4 NIETZSCHE, F. Anticristo. Disponível em: <http://www.dominiopublico.gov.br/download/texto/ph000245.pdf>, p. 5). 5 Idem. 
de estar no mundo. Muito pelo contrário, eliminar a pluralidade de tipos que constituem o homem, conforme pretendem muitos dos ideais da modernidade, implica uma perspectiva niveladora, algo que tão somente "contribui para mediocrizar o homem, pois nivela a todos indistintamente sob o mesmo critério e suprime a riqueza da pluralidade de diferenças" (VILAS-BOAS, 2011, p. 136137). Tal nivelamento e supressão das diferenças só faz crescer o desprezo dos indivíduos pelo comando de si próprios, o desprezo pela necessidade ao cultivo de si mesmos a favor de "uma vida cerceada dentro dos limites de uma busca anódina pelo conforto, segurança e estabilidade no interior de uma sociedade gregária” (Idem).

Pois bem, ao abdicar do cultivo de si enquanto multiplicidade de tipos, o homem conforma-se a tão somente obedecer a ordens exteriores $\mathrm{e}$ simplesmente adaptar-se aos acontecimentos e situações da vida, criando com isso repulsa às suas perturbações e conflitos (Idem). A fim de superar esta situação humana existencialmente dilacerante, o que deverá despontar na perspectiva de Nietzsche é um tipo de formação que além de privilegiar o cultivo desta multiplicidade de tipos que é o homem, deve lhe conferir também a possibilidade de (re)valorar tudo o que a ele se impôs como absoluto. Para todos os efeitos, é fundamentar atentar que "a simples presença de pluralidade de tipos e de formas de valoração não significa, necessariamente, que se tenha algum tipo de homem superior. A ideia de elevação do homem pressupõe a pluralidade disposta como conflito" (PASCHOAL, 2009, p. 151). Isto significa que se o empenho em cultivar a si mesmo confere ao homem a possibilidade de intensificar os distintos tipos que o constituem, como tal, isto se efetiva tão logo ele se reconheça como o locus mais privilegiado à instauração de um espaço agonístico que ocorre entre as pluralidades que ele mesmo é. Nesse sentido, num movimento oposto aos ideais da modernidade e, portanto, da pequena política, a grande política em Nietzsche considera o homem como uma grande arena de batalha onde nele se privilegia o caráter conflitante entre os mais diversos tipos e possibilidades, haja vista ser uma completa ingenuidade afirmar “assim e assim deveria ser o homem!” (NIETZSCHE, 2006, p. 37), sobretudo porque "a realidade nos mostra uma fascinante riqueza de tipos, a opulência de um pródigo jogo e alternância de formas - 'O indivíduo é, de cima a baixo, uma parcela de fatum [fato, destino], uma lei mais, uma necessidade mais para tudo que virá e será” (Idem).

O Nietzsche jovem investiu por muito tempo em uma ideia de cultura superior, ancorada na perspectiva de uma Bildung que se diferenciava das intenções do Estado justamente por considerar uma formação humana antípoda àquela oferecida pelas instituições de ensino alemãs. Apesar do controle 
institucional exercido pelo Estado sobre o sistema educacional, Nietzsche destaca a força da educação por meio das instituições, visando então garantir o acesso ao conhecimento científico e se possível convertê-lo em Arte.

Apesar da aposta inicial na Bildung, o filósofo observa que predomina uma ideia de cultivo que apenas atravessa o indivíduo pois o que se estabelece é a vontade de poder e força, ou do Estado, ou das instituições de formação. Podemos afirmar que Nietzsche, mesmo desiludido com tais forças, não as dispensa, mas inicia uma nova viagem que exige pensar o cultivo de si e não o que terceiros desejam cultivar em nós. Afinal o que em nós é fruto de nossa própria vontade de potência? $\mathrm{O}$ que em nós é fruto do cultivo estrangeiro para produzir uma orientação em nossa vida?

Nesse cenário o conceito de cultivo merece a nossa atenção. Se o cultivo tem muitos sentidos e significados, qual teria sido desenvolvido por Nietzsche? Desejamos argumentar a favor da ideia de que o filósofo alemão abandona, nos textos de 1888, sua grande ambição de que a "cultura superior" pudesse se concretizar a partir de uma reformulação no interior das instâncias da cultura vigente e começa a fazer nova trajetória que sugere a elevação do tipo homem orientada pela noção de cultivo de si. Trata-se de uma mudança de perspectiva que em parte secundariza os grandes empreendimentos da cultura, pois seu entusiasmo é aplacado por esta esperança, ao passo que Nietzsche coloca agora no centro de suas expectativas a formação de indivíduos de exceção capazes de impor a si mesmos e a partir de si mesmos um novo critério de seleção e cultivo.

Assim sendo, levando em consideração as variações da noção de Züchtung (cultivo) nas obras publicadas a partir de 1888 podemos afirmar que, em alguma medida, mais do que uma preocupação com uma cultura superior, Nietzsche preocupa-se com a elevação do indivíduo e por isso com uma ideia do cultivo de si. Podemos até arriscar que Nietzsche está afirmando que o destino da cultura não está mais nas mãos do Estado e/ou em mãos institucionalizadas que antecipadamente decidem sobe quais cultivos devem orientar os humanos. Steiner (2005, p. 12) também nos alerta: " o território da alma tem sempre seus vampiros”. Cabe sempre dizer que não se trata de criar um ambiente de terra devastada fazendo uma apologia à destruição do já existente. Contudo nosso filósofo na sua maturidade enxerga uma novidade no entre-lugar, ou seja naquilo que sempre já nos orienta e na possibilidade de produzir em nós mesmos outra orientação diante de tantas que nos atingem. 
A metáfora do jardineiro em Nietzsche talvez possa nos ajudar a pensar a dimensão do cultivo que se altera em Nietzsche. Segundo Constâncio (2014) o jardineiro que estrutura seu caráter, com isso cria sua individualidade não é um sujeito nem no sentido cartesiano e nem num sentido kantiano. Em suas reflexões, Constâncio está preocupado em refletir sobre o que somos livres para fazer e parece que o jardineiro nos aponta algumas saídas. Aquilo que floresce depende muito do que já sabemos ou somos ensinados pela tradição do cultivo e dos valores. Contudo ao invés de adaptar-se aos valores já existentes, existe ainda mais vida para florescer e não conhecemos todas estas possibilidades. Nos humanos o que pode florescer com vida está no corpo, no organismo como um todo. Fomos cultivados para muitas coisas, mas tem mais para nascer, florescer. Seria o jardineiro uma espécie de mestre? Quantos desses mestres cruzaram nossas vidas?

Como diz Meirelles na defesa de uma formação centrada na ideia do cultivo de si,

\begin{abstract}
não se trata mais de esperar pelo Übermensch anunciado por Zaratustra, nem pelo "homem redentor" esboçado em Genealogia da Moral. Para Nietzsche, nesse momento, trata-se da tarefa de tornar-se si mesmo, de devolver ao indivíduo a prerrogativa de cuidar de si, autoformar-se, cultivar a si mesmo como forma de autoelevação para além da moral gregária e das ideias modernas. Na medida em que desaparecem quase que completamente nos textos de 1888 a figura do além-do-homem, as análises sobre o ressentimento e a compaixão; e a expectativa de uma cultura elevada parece dar lugar aos homens de exceção (AusnahmeMenschen), somos levados a pensar o individuum como lugar privilegiado do cultivo das virtudes nobres. Isso parece se confirmar pelo fato de Nietzsche manter, com mais precisão e de modo mais orientado, as noções de cultivo e seleção (Züchtung), disciplina (Zucht) e formação (Bildung) não em relação à cultura em geral ou ao "povo", mas em relação aos indivíduos de exceção. (MEIRELLES, 2015, p. 373)
\end{abstract}

Meireles afirma que no livro Ecce Homo, Nietzsche apresenta todo o seu esforço argumentativo para "convencer o leitor sobre o modo como sua perambulação pelas várias morais e sua frequentação no movimento da décadence demonstraram, no fim das contas, que a afirmação incondicional do mundo e da vida é prerrogativa dos indivíduos de exceção” (Ibidem, p. 374). 


\section{CONSIDERAÇÕES FINAIS}

Perguntas que ecoam: Seria o indivíduo o antípoda do coletivo? A harmonia se dá apenas na homogenia? O bom é o altruísta? Qual o papel do nobre? Superação e autossuperação, são termos superados?

Como construir uma educação que privilegie a multiplicidade no lugar da unidade, a aparência no lugar da essência, o simulacro no lugar do ser, que renuncie às ideias de libertação, autonomia, emancipação e tantos outros cantos de sereia. Virando as costas para as epistemologias da verdade, um processo educativo fundamentado sem fundamentos últimos, sem princípios transcendentes, mas contingentes, eventuais, efêmeros.

Flertamos com a hipótese que há uma imbricação intrínseca entre pequena política, moral do rebanho e educação humanista/dogmática, sendo assim, outra educação seria possível com a grande política gestada a partir de uma moral nobre, considerando a formação como a agonística que nos provoque a produzir constantes deslocamentos, evidenciando e hierarquizando as múltiplas perspectivas que nos atravessam.

O educador é, em parte, um representante desses possíveis deslocamentos, pois vem ao longo do tempo resistindo à sedução de muitas totalidades. Não são todos, talvez nem a maioria, mas eles estão aí, resistindo. Usam seus martelos para afirmar um estilo de ser educador, por vezes avesso aos apelos institucionais, aos projetos político-pedagógicos, às políticas públicas. Desejam dar a si mesmos um estilo, encontrar e afirmar uma justificação estética para a própria existência, dar lugar a uma prática menos apressada, suportar o silêncio para que o pensar esteja vivo, outra formação apareça. A vida na escola, na academia, pode fazer muito sentido, mas ela exigirá outros temperos, outras medidas e o enfrentamento de muita mediocridade, de muitas totalidades, ao mesmo tempo que exigirá que o uso do martelo possa criar outra grandeza a tal ponto estética que seja possível desejá-la viver infinitamente em razão de sua exuberância e de sua vibração. Nietzsche afirma a necessidade de ruminar, deixar que as coisas se aproximem para pensar com sossego e tempo para então fazer fluir e afirmar experiências novas, singulares, não totalizantes, erguendo vozes dissonantes, que talvez estabeleçam outros horizontes para a educação. 


\section{REFERÊNCIAS}

ANSEL-PEARSON, K. Nietzsche como pensador político: uma introdução. Trad. Mauro Gama e Cláudia Martinelli Gama. Rio de Janeiro: Jorge Zahar, 1997.

BARRANECHEA, M. A. de. Nietzsche e a "Grande Política": memória, educação e criação de valor. Ethica, Rio de Janeiro, v. 11, n. 1 e 2, p. 93-110, 2004 .

; DIAS, M. J. Entre a memória e a política: Nietzsche e Arendt na atualidade. Cad. Nietzsche, São Paulo, n. 33, p. 301-326, 2013.

CONSTÂNCIO, J. O que somos livres para fazer ? Reflexão sobre o problema da subjetividade em NNIetzsche. IN: Marton, S.;Branco, M.J.M; Constâncio, J. Sujeito décadence e arte- Nietzsche e a modernidade. Tinta da China. Lisboa/Rio de Janeiro. 2014

LARROSA, J. Nietzsche e a educação. Trad. Alfredo Veiga-Neto. Belo Horizonte: Autêntica, 2002.

2004.

LOPES, A. D. A questão da vontade nas análises políticas de Nietzsche.

Trágica: Estudos sobre Nietzsche, v. 2, n. 1, p. 1-19, 1ํㅗ sem 2009.

MEIRELES, I. Elevação (Erhörung) e cultivo (Züchtung) na filosofia de Nietzsche. Revista ethic@, Florianópolis, v. 14, n. 2, p. 367-381, dez. 2015.

NIETZSCHE, F. W. Humano, demasiado humano: um livro para espíritos livres. Tradução de Paulo César de Souza. São Paulo: Companhia das Letras, 2000 .

Ecce homo: como alguém se torna o que é. Trad. Paulo Cesar de Souza. São Paulo: Companhia das Letras, 2001.

NIETZSCHE, F. W. Além do bem e do mal: prelúdio a uma filosofia do futuro. Trad. Paulo César de Souza. São Paulo: Companhia de Bolso, 2005. 
Crepúsculo dos ídolos. Trad. Paulo Cesar de Souza. São Paulo:

Companhia das Letras, 2006.

Aurora: reflexões sobre os preconceitos morais. Trad. Paulo Cesar de Souza. São Paulo: Companhia das Letras, 2008.

Genealogia da moral: uma polêmica. Tradução de Paulo César de Souza. São Paulo: Companhia das Letras, 2009.

Fragmentos póstumos 1885-1887: v. VI. Tradução de Marco Antônio

Casanova. Rio de Janeiro: Forense Universitária, 2013.

STEINER, George. Lições dos Mestres. Editora Record. Rio de Janeiro/SP. 2005 .

STEGMAIER, W. As esperanças de Nietzsche em relação à Filosofia e à atualidade. Revista eletrônica SOFIA, Vitória (ES), v. 3, n. 2, jul.-dez. 2014.

VIESENTEINER, J. L. "Cultivo" e vivência (Erlebnis): premissas à construção da tarefa de 'tornar-se o que se é' em Nietzsche. Cadernos de Ética e Filosofia Política, v. 17, n. 2, p. 203-227, 2010.

VILAS BÔAS, J. P. S. Nietzsche e a polêmica em torno da Grande Política: Por uma ética de superação do niilismo. Theoria - Revista Eletrônica de Filosofia, v. 3, n. 6, 2011.

Recebido em 24/08/2018

Aprovado em 17/01/2019 